Chapman University

Chapman University Digital Commons

Pharmacy Faculty Articles and Research

School of Pharmacy

2012

\title{
Effects of Simulations on the Learning of Pharmacokinetic Concepts
}

Reza Mehvar

Chapman University, mehvar@chapman.edu

Follow this and additional works at: http://digitalcommons.chapman.edu/pharmacy_articles

Part of the Other Pharmacy and Pharmaceutical Sciences Commons, and the Science and Mathematics Education Commons

\section{Recommended Citation}

Mehvar R, Effects of Simulations on the Learning of Pharmacokinetic Concepts. Curr. Pharm. Teach. Learn., 4.4:278-284 (2012). doi:10.1016/j.cptl.2012.05.008

This Article is brought to you for free and open access by the School of Pharmacy at Chapman University Digital Commons. It has been accepted for inclusion in Pharmacy Faculty Articles and Research by an authorized administrator of Chapman University Digital Commons. For more information,

please contact laughtin@chapman.edu. 


\section{Effects of Simulations on the Learning of Pharmacokinetic Concepts}

\section{Comments}

NOTICE: this is the author's version of a work that was accepted for publication in Currents in Pharmacy Teaching and Learning. Changes resulting from the publishing process, such as peer review, editing, corrections, structural formatting, and other quality control mechanisms may not be reflected in this document. Changes may have been made to this work since it was submitted for publication. A definitive version was subsequently published in Currents in Pharmacy Teaching and Learning, volume 4, issue 4, in 2012. DOI: $10.1016 /$ j.cptl.2012.05.008.

\section{Copyright}

Elsevier 


\section{Effects of simulations on the learning of pharmacokinetic concepts}

Objective: Although the use of computer simulations in pharmacokinetics courses is not new, the data on the effects of simulation on student learning are scarce. The objective of this study was to design and evaluate the use of Web-based simulations on the learning of pharmacokinetic concepts by doctor of pharmacy (PharmD) students.

Method: Six online modules were designed to allow the instructor and students to use "what-if" scenarios for understanding the effects of various dosage regimens and/or pharmacokinetic parameters on the plasma concentration-time courses of drugs. The designed modules were intravenous and oral pharmacokinetic concepts, bioavailability, intravenous infusion, multiple dosing, nonlinear pharmacokinetics, and hepatic clearance. The effects of simulation modules on student learning were tested in pre/post tests for the multiple dosing module and in mid-term assessments for the hepatic clearance concepts. Additionally, the students' perceptions of the effectiveness of the modules were determined using a survey.

Results: Compared with a pretest, a 10-min use of the multiple dosing module in class by students resulted in a $21 \%$ improvement in the performance of the students in a posttest. Additionally, the use of the hepatic clearance module outside the classroom was associated with a $16 \%$ improvement in their performance in a mid-term assessment. Finally, the students' responses to an attitudinal survey indicated that students believe the use of modules improves their learning of pharmacokinetic concepts.

Conclusions: Online simulation modules dealing with pharmacokinetic concepts improve student learning of pharmacokinetics.

Keywords: Pharmacokinetics; Simulation; Active learning; Online modules; Pharmacokinetic concepts 


\author{
Reza Mehvar, PharmD, PhD \\ Texas Tech University Health Sciences Center School of Pharmacy
}

Corresponding Author:

Reza Mehvar, PharmD, PhD

Department of Pharmaceutical Sciences

School of Pharmacy

Texas Tech University Health Sciences Center

1300 S. Coulter

Amarillo, TX 79106

E-mail address: reza.mehvar@ttuhsc.edu

Financial Disclosure Statement: No funding has been received for this study.

Conflict of Interest Disclosure Statement: The author does not have any conflict of interest. 


\section{Introduction}

Most of the efforts of the instructors of pharmacokinetics in the professional PharmD programs are directed towards estimation of pharmacokinetic parameters and design of dosage regimens (i.e., calculations). However, an understanding of major pharmacokinetic concepts is also critical in prediction of the effects of changes in dosage regimens, disease states, and interacting drugs on the plasma concentration-time courses of drugs. Therefore, a number of instructors have used simulations to facilitate student learning of pharmacokinetic concepts. ${ }^{1-11}$ This is consistent with the views of the Accreditation Council for Pharmacy Education (ACPE), which considers the use of high-tech simulations in teaching as one of the innovative methods to prepare future pharmacists for an expanded role in health care. ${ }^{12}$

Pharmacokinetics simulations allow students to explore "what-if" scenarios by examining the effects of changes in the dosage regimen and/or physiologic/pharmacokinetic parameters on the shape of the drug plasma concentration-time course in a self-directed learning environment. Whereas the earlier works in the area of pharmacokinetics simulations used stand-alone programs, ${ }^{1-7,9,11}$ more recently instructors use Web-based programs for simulation. ${ }^{8,10}$ The Webbased programs are advantageous over the stand-alone programs because they do not require downloading and installing platform (Windows ${ }^{\circledR}$ or Macintosh ${ }^{\circledR}$ )-specific programs. Additionally, the availability of relatively easy-to-use Web-based design programs allows instructors to develop their own online simulation modules according to the need of their students. Despite availability of many stand-alone and a few Web-based simulation programs, assessment of these programs in terms of student performance is limited. ${ }^{8}$ Therefore, the purpose of the current communication is to report on the design, implementation, and assessment of such modules for use in a pharmacokinetics course offered to PharmD students at Texas Tech 
University School of Pharmacy. Our hypothesis was that the use of simulation modules improves student learning of pharmacokinetic concepts.

\section{Methods}

\section{Simulation modules}

Simulation modules were developed by the instructor using a commercially-available, Web-based database program. The modules consist of three windows as outlined in Fig. 1. In the first window, the users select one of the simulation modules, which leads to the Input Parameters window. The Input Parameters window allows the input of the pharmacokinetic and dosage regimen parameters for two scenarios for side-by-side comparison of the results. After entering the input parameters, the users view the Output Parameters window, which consists of estimated pharmacokinetic parameters and graphs of plasma concentration-time courses and/or other relevant graphs (e.g., AUC versus dose for the nonlinear kinetics module), comparing the two scenarios.

Each module contains instructions for its use, which are posted online as a hyperlink to the Input Parameters window. As an example, the instructions for the use of Multiple Dosing module are presented in Appendix 1. These instructions consist of four elements of learning objectives, input parameters, output parameters, and a step-by-step example on the application of the module using specific parameters.

\section{Role of modules in student learning}

The effect of simulations on student learning in a pharmacokinetics course, which is offered synchronously to local (Amarillo) and distant (Abilene) campuses, was tested using two 
modules with different assessment methodologies. For the Multiple Dosing module, a pre/post test assessment design was used to test the effects of the use of the module by students during a limited time (10 min) in class. Briefly, during a class period devoted to multiple dosing, the topic was briefly introduced for the first time by the instructor without the use of simulations.

Subsequently, students were given a 9-question, multiple-choice quiz during the same session. The questions were related to concepts in multiple dosing, dealing with the effects of changes in the dose and/or dosage interval on the degree of accumulation, fluctuation, and average steadystate concentration (learning objective 2, Appendix 1). The students did not receive any feedback on their answers or their grades in the pretest. After completion of the pretest, students were allowed 10 minutes to use the online module in class using their individual laptops. They were asked to use the instructions for the module (Appendix 1) to conduct the simulations, without knowing that there would be a posttest. Afterward, the same quiz was re-administered, and the pretest and posttest grades were calculated. A two-tailed, paired t-test was used to compare the pre- and posttest grades for all students. Additionally, a two-way ANOVA with Bonferonni multiple comparisons was used to test the effects of simulation (pre- and posttest) and location (Amarillo and Abilene) on the performance of students in the quiz.

In the second assessment, the effect of the use of simulations by students outside the class on their learning was tested using the Hepatic Clearance module. The simulation database was first examined to identify students who voluntarily used this module during a 4-week period starting with the introduction of the topic in class and ending with a mid-term examination. The exam consisted of 25 questions, 4 of which were directly related to the clearance concepts covered in the Hepatic Clearance simulation module. Subsequently, the effects of the use of the simulation module on the performances of the students in the overall exam and the questions 
related to the clearance concepts were evaluated. The differences between the grades of students who did or did not use the simulations on their own were determined using a two-tailed, unpaired t-test.

In addition to the performance data, an attitudinal survey was administered at the end of semester to measure the student perceptions of the usefulness of the simulation modules in an anonymous fashion. The survey consisted of 5 Likert-scale questions and 1 open-ended question for comments. Chi square analysis was used to test the differences between the responses of the students in Amarillo and Abilene to the survey questions.

The study was approved by the author's Institutional Review Board under the exempt status.

\section{Results}

\section{Simulation modules}

Overall, six simulation modules were developed for incorporation into the course, which is offered synchronously to the second-year pharmacy students on both local (Amarillo) and distant (Amarillo) campuses. The simulation modules were as follows:

1. Intravenous and Oral Pharmacokinetic Concepts

2. Bioavailability

3. Intravenous Infusion

4. Nonlinear Kinetics

5. Multiple Dosing

6. Hepatic Clearance 
As an example, the Input and Output Parameters windows for the Multiple Dosing module are presented in Figures 2 and 3, respectively. The instructions for the module (Appendix 1) would direct the students to enter specific values for the dosage regimen and pharmacokinetic parameters for two scenarios (Case I and Case II) (Fig. 2) and observe the effects of changing one or more parameters on the pharmacokinetic parameters and plasma concentration-time curves (Fig. 3). The instructions in the examples are designed to achieve the stated learning objectives for each module. To emphasize the relationship among major pharmacokinetic parameters, ${ }^{13}$ all the modules are designed so that students enter volume of distribution and clearance of drugs (Fig. 2), as opposed to elimination rate constant and volume of distribution. For the multiple dosing module, students also enter the pharmacodynamic parameters minimum effective and minimum toxic concentrations (Fig. 2). Although these latter parameters would not affect the results, they are helpful for understanding the concept of fluctuation when viewing the graphs (Fig. 3). By pressing “Change Input Parameters” button (Fig. 3), students can return to the Input Parameters window (Fig. 2) and change other parameters for a new simulation.

\section{Role of modules in student learning}

The 10-minute use of the Multiple Dosing module in class by students themselves improved the overall performance of the students (mean \pm SEM) from $58.3 \pm 1.9 \%$ in the pretest quiz to $70.8 \pm 1.9 \%$ in the posttest quiz $(p<0.0001)$, which is equivalent to a $21 \%$ improvement in the performance relative to the pretest score. Additionally, the two-way ANOVA indicated whereas there was no effect of location on the performance of students, the module significantly improved the performance of students in both Amarillo and Abilene (Fig. 4). 
As for the Hepatic Clearance module, 58 students (46\%) used and 69 students (54\%) did not use the simulation module outside the classroom during the 4-week period between the introduction of the topic in class and the mid-term examination (Table 1). Whereas those students who used the simulation module achieved an absolute 6\% higher grade on the overall exam, compared with those who did not use the module, the magnitude of the absolute difference between the two groups was much larger $(15.5 \%)$ with regard to the four clearance concepts questions (Table 1). It may be argued that the group who used the simulation is academically superior to that who did not use the simulation, hence resulting in higher performance of this group in the clearance concepts questions. To remove this bias between the two groups, performance of the students on the clearance concepts questions was corrected by their performance on the remaining 21 questions in the exam. This was achieved by dividing the clearance concept grade by the grade for the remaining questions in the exam for each student. As demonstrated in Table 1, the unbiased, corrected clearance concepts grades for those who used the simulation were $16 \%$ higher relative to those who did not use the module during the monitored period.

The responses of the students to the survey questions regarding the use of simulation modules are presented in Table 2. Eighty out of 89 students (90\%) in Amarillo and 37 out of 39 students (95\%) in Abilene responded to the survey. More than $75 \%$ of students agreed or strongly agreed that the use of simulations by the instructor during the class sessions improved their learning of pharmacokinetic concepts (question 1). A similar number of students also (strongly) agreed that the use of in-class simulations by the instructor should be continued (question 2). However, students were less enthusiastic about the use of simulations on their own outside the class, as demonstrated by their answers to questions 3-5. Specifically, students were 
almost split in their opinions as to making the use of simulations outside the classroom mandatory (question 5). As for the two campuses, except for question 2, which Abilene students rated more favorably, the responses to the survey questions were similar (Table 2). The students' responses to the open-ended question regarding the simulations were in general agreement with the quantitative data presented in Table 2. A number of students commented that they felt the use of simulations by the instructor during the class was more effective than their own use of simulations outside the classroom. Some students commented that when they tried to use the simulations on their own, they got confused, but the use of simulations by the instructor was clear and easy to understand. Overall, students' comments indicate that they view the simulations as an effective learning tool in the course.

\section{DISCUSSION}

The use of computers and the Internet to facilitate student learning in higher education has increased substantially during the last decade. In addition to personal computers owned by students, it is not unusual any more to see high-tech classrooms, equipped with computers or other technological devices at the students desks, in most colleges and universities. At Texas Tech School of Pharmacy, students are required to bring their own laptops to the classroom, which is equipped with wired or wireless Internet access. Therefore, the use of online educational materials by students and faculty is possible both inside and outside the classroom. To take advantage of this opportunity, online simulation modules were developed to aid students' learning of pharmacokinetic concepts. The simulation modules were used by the instructor, during class sessions to illustrate important concepts, and also were made available to students, for use inside and outside the classroom. It was hypothesized that the use of the 
simulations by the instructor during the class time would improve students' understanding of the concepts, particularly those who are visual learners. Additionally, it was assumed that the use of the modules by students themselves would improve their learning because of their active involvement in their education. Evaluative data presented here (Fig. 4 and Tables 1 and 2) are in agreement with these hypotheses, suggesting the usefulness of the modules as a learning tool in this course.

Obtaining valid and accurate performance data to evaluate the effects of a learning intervention, such as simulation modules, is difficult without multiple interruptions in regular class sessions. Therefore, the effects of the use of only one module by students were tested during the class time. The use of the Multiple Dosing simulation by students in class for $10 \mathrm{~min}$ resulted in an absolute gain of $12.5 \%$ in the posttest grades, which is equivalent to a relative gain of $21 \%$ over the pretest value of $58.3 \%$. However, this may be an underestimation of the true effect of the module for two reasons. First, in this assessment, students were allowed to use the module only during a limited time $(\sim 10 \mathrm{~min})$ in the classroom because of time limitations of the class session. Additionally, this assessment only measured the effect of the use of the module by the students and not that related to the in-class use of the module by the instructor. As demonstrated by the student survey data (Table 2), including student comments, most students believed that the use of the modules by the instructor was very effective. Therefore, the actual impact of the module on the learning of multiple dosing concepts may have been more than that reflected in the presented performance data (Fig. 4).

To complement the data obtained by the limited use of the Multiple Dosing simulation module in class, additional data were also obtained from the out-of-class use of the simulations by the students. For this purpose, a second set of performance data (Table 1) was generated using 
a different methodology and module (Hepatic Clearance Concepts). In agreement with the pre/post test data (Fig. 4), the data in Table 1 clearly indicate that the voluntary use of the simulation modules outside the classroom by students also significantly improves their learning of pharmacokinetic concepts assessed in regular examinations.

Although the use of simulations in pharmacokinetics courses are not uncommon, ${ }^{1-11}$ the reported evaluative data are mostly based on attitudinal surveys, which measure the perception of the users regarding their effectiveness. Indeed, aside from a report by this author on Bayesian analysis,${ }^{10}$ the author is aware of only one study of pharmacokinetic simulations that reports performance data. ${ }^{8}$ In that study, Hedaya ${ }^{8}$ administered a 10 -question pretest to second-year pharmacy students to evaluate the use of an online simulation module. The students were then given unlimited time to use online pharmacokinetics simulations and some explanatory materials until they felt comfortable with the material, before taking the test (posttest) again. The students' grades were improved from an average of 5.4 to $8.9,{ }^{8}$ which is a much greater improvement than that observed in our pre/post test design study (Fig. 4). Two major differences between the Hedaya's report and ours may have contributed to the differences in the performance data. First, in our study, students were given only 10 min, as opposed to unlimited time allowed by Hedaya, to work on the simulations. Second, our students were not given any additional reading materials during the pretest and posttest period to improve their understanding of the concepts.

Nevertheless, despite more limitations, our study revealed a significant, although more moderate, effects of the simulations on students learning.

Although the performance and survey data clearly indicate the usefulness of the currently-designed simulation modules, several improvements are planned for the future. These include design of new simulation modules for topics that were not covered by the current six 
modules. Additionally, the instructions for the use of the modules could be further improved by, for instance, expanding the examples and interpretation of the results. Further, to allow students to measure their level of understanding the concepts, the author plans to add self-assessment exercises to the modules. Finally, to increase the use of the modules by the students on their own, the instructor intends to make the modules a more integral part of the class activities. For example, specific questions could be added to the current practice problems used in the class, which can be answered by the use of simulations.

\section{Conclusions}

Online simulation modules for understanding pharmacokinetic concepts were designed and implemented in a pharmacokinetics course offered to second-year pharmacy students. The modules were used by both the instructor, for demonstrations during the class sessions, and students, on their own time. The modules were evaluated by both performance data and an attitudinal survey, both supporting the hypothesis that the use of simulation modules improves student learning of pharmacokinetic concepts. 


\section{References}

1. Sullivan T. Computer-assisted instruction in pharmacokinetics: the SIMU series. Am J Pharm Educ. 1988;52:256-258.

2. DiFazio MH, Shargel L. A mathematical utility program to facilitate student comprehension of the pharmacokinetics of the one compartment model. Am J Pharm Educ. 1989;53:50-53.

3. Robbins DK, Wedlund P, Williams J. Sim.Bas: A user-friendly computer program which simulates drug concentration-time profiles. Am J Pharm Educ. 1989;53:138-140.

4. Sullivan T. Use of MathCAD in a pharmacokinetics course for pharmD students. Am J Pharm Educ. 1992;56:144-147.

5. LeBlanc PP, Aiache JM. Problem-based and computer-assisted learning of pharmacokinetics. Am J Pharm Educ. 1994;58:94-95.

6. Bolger MB. Cyber Patient ${ }^{(\mathrm{TM})}$ : a multimedia pharmacokinetic simulation program for case study generation in a problem-solving curriculum. Am J Pharm Educ. 1995;59:409-416.

7. Li RC, Wong SL, Chan KKH. Microcomputer-based programs for pharmacokinetic simulations. Am J Pharm Educ. 1995;59:143-147.

8. Hedaya MA. Development and evaluation of an interactive Internet-based pharmacokinetic teaching module. Am J Pharm Educ. 1998;62:12-16.

9. Wu-Pong S, Cheng CK. Pharmacokinetic simulations using cellular automata in a pharmacokinetics course. Am J Pharm Educ. 1999;63:52-55. 
10. Mehvar R. Development and application of an on-line module for teaching Bayesian forecasting principles in a clinical pharmacokinetics course. Am J Pharm Educ. 2000;64:121-125.

11. Munar MY, Singh H, Belle D, Brackett CC, Earle SB. The use of wireless laptop computers for computer-assisted learning in pharmacokinetics. Am J Pharm Educ. 2006;70:Article 04.

12. Accreditation Council for Pharmacy Education. ACPE Update. Vol 8; 2010:2

13. Mehvar R. The relationship among pharmacokinetic parameters: effects of altered kinetics on the drug plasma concentration-time profiles. Am J Pharm Educ. 2004;68:Article 36. 


\section{Appendix 1. Instructions for multiple dosing simulations}

\section{Learning objectives}

1. Predict the effects of loading dose on the plasma concentration time profile of drugs after multiple dose administration.

2. Predict the effects of alterations in dose and/or dosage interval on the plasma concentration fluctuation, accumulation, and the maximum, minimum, and average steady state concentrations with reference to the therapeutic range.

\section{Input Parameters}

- Kinetic Parameters: Clearance (CL), volume of distribution (V), minimum effective concentration (MEC), and minimum toxic concentration (MTC).

- Dosage Regimen Parameters: Dose, dosage interval $(\tau)$, loading dose $\left(D_{L}\right)$, and the number of doses to be simulated $(\mathrm{N})$.

\section{Output Parameters}

- The following parameters are calculated by the program: Dosing rate, plasma half life $\left(\mathrm{t}_{1 / 2}\right)$, average steady state concentration $\left(C_{\text {ave }}^{\infty}\right)$, maximum concentration at steady state $\left(C_{\max }^{\infty}\right)$, minimum concentration at steady state $\left(C_{\min }^{\infty}\right)$, and accumulation factor $\left(\mathrm{R}_{\mathrm{acc}}\right)$. Additionally, graphs of plasma concentration-time data are presented.

\section{Example}

\section{Effects of Loading Dose}

1. Enter required kinetic parameters (CL, V, MEC, and MTC) for Case I. For example: CL, $1.155 \mathrm{~L} / \mathrm{hr} ; \mathrm{V}, 10 \mathrm{~L} ; \mathrm{MEC}, 10 \mathrm{mg} / \mathrm{L}, \mathrm{MTC}, 20 \mathrm{mg} / \mathrm{L}$. 
2. Enter dosage regimen parameters for Case I. For example: Dose, $100 \mathrm{mg} ; \tau, 6 \mathrm{hr}$; $\mathrm{D}_{\mathrm{L}}$, none (leave blank); and N, 6. Please do not enter any value for Case II at this time.

3. Press the "simulate" button.

4. Observe the plasma concentration-time data. What is the degree of accumulation of the drug using this regimen?

5. Please calculate an appropriate loading dose to reach steady-state immediately (maintenance dose $\left.x R_{a c c}\right)$.

6. Now press the "Change Input Parameters" button and change the loading dose value for Case II to the calculated loading dose. For Case I, do not enter a loading dose.

7. Press the "Simulate" button and observe the plasma concentration time data for Case I and II. What are the differences between the two cases with regard to the time to reach steady state, $C_{\text {ave }}^{\infty}, C_{\max }^{\infty}$, and $C_{\min }^{\infty} ?$

8. Now, for Case II administer a loading dose which is more or less than necessary. What are the effects of inappropriate loading doses on the plasma concentration-time profiles?

\section{Alterations of Dose and/or Dosage Interval}

1. Please keep data for Case I as those above.

2. For Case II, change the dose to $200 \mathrm{mg}$ with no bolus dose. Observe the plasma concentration-time profiles. What is the effect of an increase in dose on the degree of accumulation, fluctuation, time to reach steady-state, and maximum, minimum, and average plasma concentrations?

3. Now for Case II, change the dose back to $100 \mathrm{mg}$ (like Case I) and only increase the dosage interval to $12 \mathrm{hr}$. Observe the plasma concentration-time profiles. What is the effect of an 
increase in dosage interval on the degree of accumulation, fluctuation, time to reach steadystate, and maximum, minimum, and average plasma concentrations?

4. To see the effects of a simultaneous change in both dose and dosage interval, change the dose for Case II to $200 \mathrm{mg}$ and dosage interval of $12 \mathrm{hr}$. What is the effects of simultaneous changes in both dose and dosage interval (while keeping dosing rate constant) on the plasma drug concentration-time profile?

- Additional Optional Simulations: This module may also be used to observe the effects of alterations in the kinetic parameters $(\mathrm{CL}$ and $\mathrm{V})$ on the plasma concentration-time profile. 


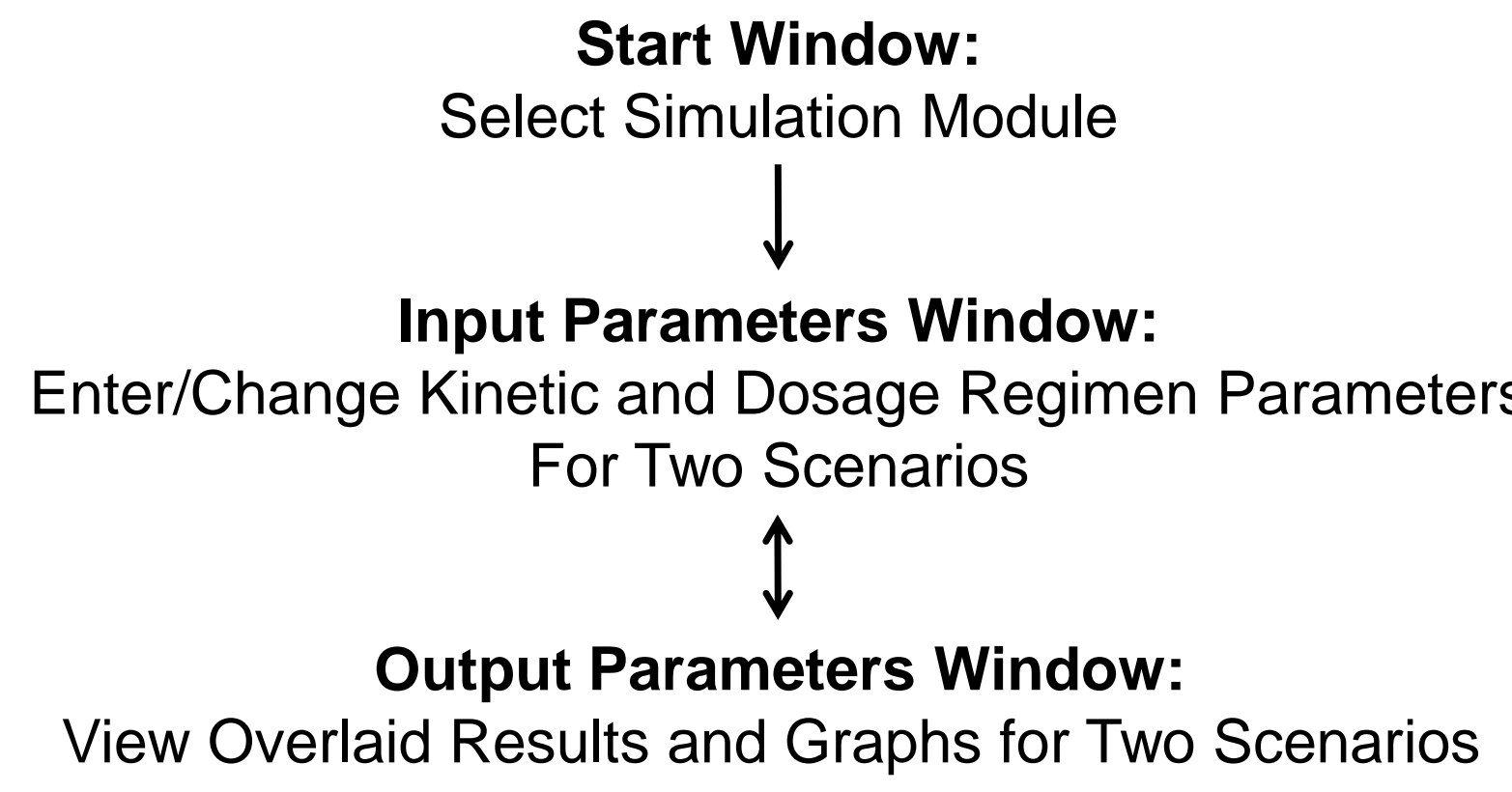

Figure 1. Outline of the three windows used in the simulation modules along with the user functions associated with each window. 


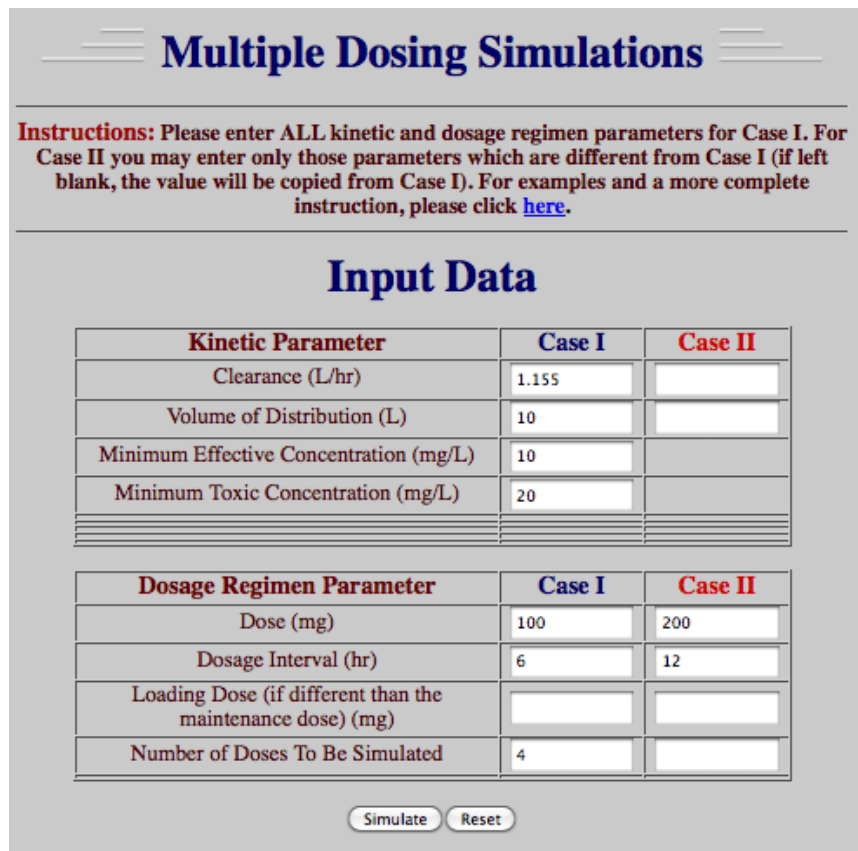

Figure 2. A screen snapshot of Input Parameters window for the Multiple Dosing simulation module. 


\section{Multiple Dosing Simulations}

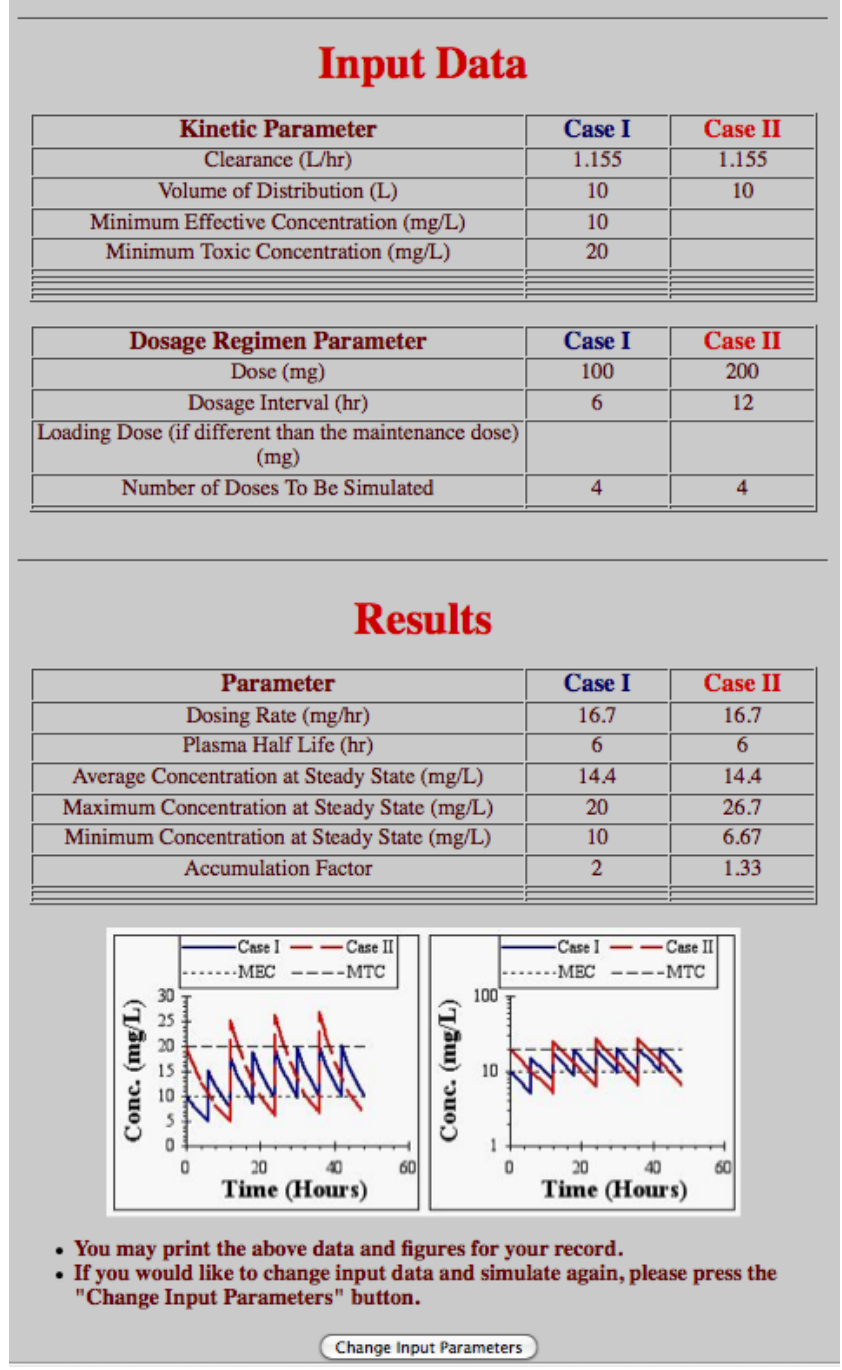

Figure 3. A screen snapshot of Output Parameters window for the Multiple Dosing simulation module. 


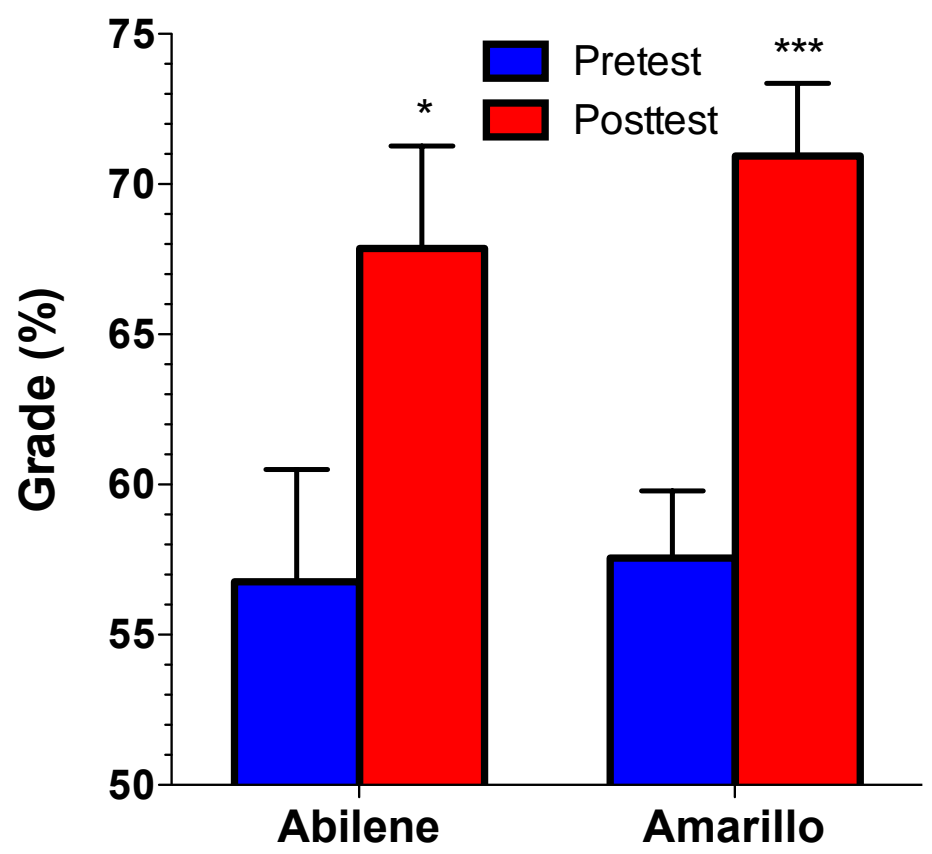

Figure 4. Pre- and posttest grades of students in Abilene $(n=37)$ and Amarillo $(n=78)$ campuses. Columns and bars represent mean and SEM, respectively. ${ }^{*}, p<0.05, * * * p<0.001$. 
Table 1

Performance of students (mean \pm SEM) in a pharmacokinetics examination consisting of 25 questions, 4 of which were related to hepatic clearance concepts covered in the simulations.

\begin{tabular}{lccc}
\hline Module & \multicolumn{3}{c}{ Grade $(\%)$} \\
Use $(n)$ & Overall exam & Clearance concepts & Corrected clearance concepts $^{\mathrm{a}}$ \\
\cline { 2 - 3 } Yes (58) & $86.3 \pm 1.3$ & $90.1 \pm 2.2$ & $107 \pm 3$ \\
No (69) & $80.1 \pm 1.5$ & $74.6 \pm 3.6$ & $92.3 \pm 4.8$ \\
$p^{\mathrm{b}}$ & 0.0031 & 0.0007 & 0.0165 \\
\hline
\end{tabular}

${ }^{\mathrm{a}}$ Clearance concepts grade: grade for the remaining questions in the exam.

${ }^{\mathrm{b}}$ Unpaired, two-tailed t-test comparison of data for those students who used simulations versus those who did not. 
Table 2

Response of students at the local (Amarillo) and distant (Abilene) campuses to survey questions about the simulation modules $(n=80$ out of 89 students in Amarillo and 37 out of 38 students in Abilene).

\begin{tabular}{|c|c|c|c|c|c|c|c|}
\hline \multirow[t]{2}{*}{ Question } & \multirow[t]{2}{*}{ Campus $(n)$} & \multicolumn{5}{|c|}{ Response (\%) } & \multirow[t]{2}{*}{ Mean $^{2}$} \\
\hline & & $\begin{array}{c}\text { Strongly } \\
\text { agree }\end{array}$ & Agree & Neutral & Disagree & $\begin{array}{l}\text { Strongly } \\
\text { disagree }\end{array}$ & \\
\hline \multirow{2}{*}{$\begin{array}{l}\text { 1. The in-class simulations by the instructor } \\
\text { helped me learn the pharmacokinetic } \\
\text { concepts. }\end{array}$} & Abilene $(37)^{b}$ & 51.4 & 37.8 & 10.8 & 0 & 0 & 4.41 \\
\hline & Amarillo $(80)^{\mathrm{c}}$ & 37.5 & 37.5 & 25.0 & 0 & 0 & 4.12 \\
\hline \multirow{2}{*}{$\begin{array}{l}\text { 2. The use of simulations by the instructor } \\
\text { during the class sessions should be } \\
\text { continued. }\end{array}$} & Abilene (37) & 64.9 & 29.7 & 2.70 & 2.70 & 0 & $4.57^{\mathrm{d}}$ \\
\hline & Amarillo (80) & 40.0 & 33.8 & 25.0 & 1.25 & 0 & $4.12^{d}$ \\
\hline \multirow{2}{*}{$\begin{array}{l}\text { 3. I frequently used the simulation modules } \\
\text { outside the classroom. }\end{array}$} & Abilene (37) & 13.5 & 32.4 & 29.7 & 18.9 & 5.40 & 3.30 \\
\hline & Amarillo (80) & 16.2 & 31.2 & 33.8 & 18.8 & 0 & 3.45 \\
\hline \multirow{2}{*}{$\begin{array}{l}\text { 4. The use of simulation outside the } \\
\text { classroom helped me learn the } \\
\text { pharmacokinetic concepts (answer this } \\
\text { question only if you used the simulation; } \\
\text { otherwise leave blank). }\end{array}$} & Abilene (28) & 25.0 & 46.4 & 14.3 & 14.3 & 0 & 3.82 \\
\hline & Amarillo (74) & 23.0 & 36.5 & 36.5 & 4.05 & 0 & 3.78 \\
\hline \multirow{2}{*}{$\begin{array}{l}\text { 5. The use of simulations by students outside } \\
\text { the classroom should be mandatory. }\end{array}$} & Abilene (37) & 21.6 & 13.5 & 27.0 & 32.4 & 5.40 & 3.14 \\
\hline & Amarillo (80) & 18.8 & 18.8 & 36.2 & 22.5 & 3.75 & 3.26 \\
\hline
\end{tabular}

